\title{
Conformance of Malaysia E-Commerce Blogs with Quality Content Theories
}

\author{
Syahida Hassan ${ }^{1}$, Suzana Zambri ${ }^{2}$, Mohd Khairudin Kasiran ${ }^{1}$, \\ Mohamad Tarmidi Mahli ${ }^{1}$, Nor Farzana Abd Ghani ${ }^{1}$ and Muziah Muhammad ${ }^{3}$ \\ ${ }^{1}$ Universiti Utara Malaysia, Kedah, Malaysia \\ ${ }^{2}$ University of Wollongong, Australia \\ ${ }^{3}$ Kolej Komuniti Jasin, Malaysia
}

\begin{abstract}
Recently the use of blog as an e-commerce site has become popular in Malaysia. Significant changes can be seen in e-commerce usage as more people are connected to the Internet through faster broadband connection. Nonetheless, trust remains a major issue when it involves online transaction. Information displayed on the blog is vital and considered as one of the important factors to gain the consumer trust. This paper is a preliminary study particularly focusing on the conformance of Malaysia E-Commerce blogs with related theories on quality online content. Samples were taken from Malaysia e-commerce blogs to identify the information that is shared by the owner of respective blogs. The information collected from the blog is then compared to the quality contents' theories. Descriptive statistic is used to describe the findings. Findings from this paper can be used as a guideline for entrepreneurs who intend to use blogs for e-commerce purposes.
\end{abstract}

Keywords: Blog, Trust, E-commerce.

\section{Introduction}

In 2010, Ministry of Information, Communications and Culture (MICC), Malaysia has commenced a broadband awareness programme aiming to emphasize the benefits of broadband to the public. With the slogan "Get Broadband, Get Everything", the programmes liaised with Malaysian National Broadband Initiative (NBI) and targeted to get more Malaysians to subscribe to the broadband services. NBI was launched by the Prime Minister as a national strategy that will bring broadband to the whole nation. It targeted to achieve $50 \%$ of household broadband penetration by the end of 2010 (SKMM, n.d). In order to achieve the target, the government had implemented several programmes, such as expanding the broadband infrastructure and services, setting up more E-Kiosk/telecentres, and providing free laptops to underserved group. As the result of such initiatives, at the end of 2010, the Malaysian government has finally announced that Malaysia's Broadband penetration had exceeded $50 \%$ ahead of schedule with $53.5 \%$ penetration.

The number of broadband users is increasing fast and it gives significant changes in ecommerce usage in Malaysia (Syahida and Khairudin, 2008). E-commerce had grown into a potential business avenue in Malaysia. According to Oh (2006), broadband will help

Copyright (c) 2012 Syahida Hassan, Suzana Zambri, Mohd Khairudin Kasiran, Mohamad Tarmidi Mahli, Nor Farzana Abd Ghani and Muziah Muhammad. This is an open access article distributed under the Creative Commons Attribution License unported 3.0, which permits unrestricted use, distribution, and reproduction in any medium, provided that original work is properly cited. Contact author: Syahida Hassan E-mail: syahida@uum.edu.my 
make e-commerce attractive to users. So, as more people connect to the Internet through faster connection, it is good news for those who venture online to sell their goods. Research done by International Data Corporation (IDC) Market Research in 2009 shows that half of Malaysia's Internet users are buying or transacting online, which equaled more than 8 million users (MalaysiaCrunch, 2010).

One of the trends in Malaysian e-commerce environment is the growing number of online shopping sites via the usage of personal blogs. The easy usage of blog's characteristics allows the store owner to conveniently customize their own online store without any cost. They used facilities to upload the picture of their products, adapting the B2C model to their online store. Nevertheless, like the other model of e-commerce, Malaysia ecommerce blogs face the same issues of trust as Malaysians generally take a long time to trust online stores (Wong, 2010; Quek, 2009).

Trustworthiness of any e-commerce website is normally the main concern of customers before they decide to make the commitment of buying a product from any online store. In the e-commerce setting, establishing trust is difficult (Syahida and Khairudin, 2008). It is because e-commerce exists in a virtual marketplace, so different kinds of trust environment are required compared to traditional physical environment. The difficulty to prove someone's physical presence and establish a direct relationship between two parties involved in the transaction caused this difference to exist.

Despite the tremendous growth of ecommerce blogs in Malaysia, relatively very few studies related to content or information in e-commerce blogs are being conducted to the date, especially in Malaysian environment. Thus, this study is intended to fill the gap. Based on literature, trust can be established with the adequate amount of information shared on e-commerce site. The quality of information on particular websites can trigger the initial trust between the two parties.

However, this paper will only cover the first part of the study as it is still on-going. The objective of this paper is to find out about the information or contents that are being highlighted by Malaysian e-commerce blog owners in their blogs, based on a few theories from the previous research. The finding of this paper is important as it can be used as a guideline to those who want to venture into online business exploiting free facilities offered by blog providers. Sellers will have the basic idea of the information they should share in their e-commerce blogs that can promote trustworthiness. It can also give an initial background of current implementation of Malaysia e-commerce via blog.

\section{Literature Review}

Blog, which is the short form of weblog, is a fast growing straightforward content management tool, allowing entries to be updated easily (Winster and Swamynathan, 2010; Gordon, 2006). Common platforms used are Blogger (www.blogger.com), Word press and Live journal (www.livejournal.com). Lu (2009) defines blog as a personal website where a user puts their review and thoughts online. They can publish their thought to public, or make it private for a certain authorized reader and allow visitors to make comments. These visitors are usually repeated visitors who are attracted to what the authors write on their blogs.

Blog has become one of the vital information sources and some of the enterprises have chosen blogs as a channel for product or service promotion (Chen, 2009). Blogs have eased communication lines to such an extent that they almost resemble a paradigm shift for the marketing and advertising community. As a new method to reach potential customers, companies such as Nike and Paramount Picture advertise through selected blogs (Hsu and Lin, 2007). 
Currently in Malaysia, according to Wong (2010), thousands of online stores are also mushrooming locally, and quite a number of them are e-commerce blog. He believes that this is uniquely a trend that only happens in Malaysia and Singapore. Nonetheless, trust issue is still the main problem in implementing e-commerce via blog in Malaysia (Quek, 2009). This is because anything can be posted on the blog, regardless of whether or not the information is reliable.

Trust represents an evaluation of information. Trust is defined as confidence in the reliability of a person or a system, regarding a given set of outcomes or events, whereby that confidence expresses faith in the probity or love of another, in the correctness of abstract principles (Hameed, 2001). The main condition that creates a need for trust is lack of full information. Therefore trust has to be created. The difficulty to prove someone's physical presence and establish a direct relationship between two parties involved in the transaction caused this difference to exist. The inability of the participants to use physical gestures such as: body language, eye contact and personal proximity to evaluate trustworthiness of each other makes the problem of establishing trust between them in cyber world even more difficult compared to brick and mortar world (Ratnasingam, 1998).

Based on the literature, content or information displayed on the e-commerce site is one of the important elements in establishing trust between seller and buyer (Nah and Davis (2002); Yang, Hu and Chen (2005); and Lumsden and MacKay (2006); Urban, Sultan and Qualls (2000); Winster and Swamynathan (2010), Hsu (2008); Proctor et al. (2003); Corbit, Thanasankit and Yi (2003)). Potential costs of poor quality web content will cause lost of sales for ecommerce site (Greg, n.d). Thus, for any ecommerce site, the information displayed should consist of quality information that is related to the product they sell.
Urban, Sultan and Qualls (2000) stressed that one of the web processes is trust in the information displayed. This is supported by Winster and Swamynathan (2010) that people and information are two important entities on the web, especially when it involves trust issues. Dwyer (2007) found that when a seller shares confidential information with a customer, the customer is more likely to trust the seller.

Establishing trust can be made through the quality content. Evaluating blog contents for the quality is important rather than the popularity of the particular blog. Wand and Wang (1996) and Wang, Reddy and Kon (1995) have listed several information or content quality characteristics, including:

- Accessibility - the availability of data, where data should be easily found or reach by the user

- Believability - The extent to which data can be counted on to be correct.

- Up to date - should be updated frequently

- Accuracy - agrees with an identified source to a desired meticulousness.

Many existing research discusses the some aspects of quality information of a website. Liu and Arnett(2000) named such quality factors as accuracy, completeness, security, reliability, customization, interactivity, ease of use, speed, search functionality, and organization. In contrast, Huizingh (2000) focused on two aspects of web quality: content and design. Wan (2000) suggested that web quality can be divided into four categories: information, friendliness, responsiveness, and reliability. Focusing on other web-related criteria, Misic and Johnson (1999) suggested finding contact information (e.g. e-mail, people, phones, and mail address), finding main page, speed, uniqueness of functionality, ease of navigation, counter, currency, wording, and color and style determined the quality of web content. 
A quality web interface or the quality of information displayed on the web could be a success factor, which determines the user's willingness to stay in a site, revisit and buy on Internet (Turban and Gehrke, 2000). Willingness to stay, revisit and buy the product is amongst the trust indicators in ecommerce implementation. This is supported by findings from several researchers (Hsu, 2008; Proctor et al, 2003; Corbit, Thanasankit and Yi, 2003) who stated that perceived quality content has a positive impact on trust.

Shergill and Chen (2005) identified four different factors perceived by online buyers that affect online purchase behaviour. The factors are (1) website design, (2) website reliability/fulfilment, (3) website customer service, and (4) website security/privacy. Initial trust usually is triggered by the characteristics of the website itself. Thus, ecommerce blog owners should know that basic contents need to be included on their blogs in order to gain the consumers' trust.

According to Proctor et al., (2003), the primary goal of content preparation for ecommerce website should include (1) what information needed, (2) how to structure and organize the information, (3) which method are best for retrieving the information, and (4) how the information should be presented to user. Literature done by Gehrke and Turban (1999) shows that the major determinant of e-commerce website design includes business content.

Nah and Davis (2002), Yang, $\mathrm{Hu}$ and Chen (2005), and Lumsden and MacKay (2006) had come up with model and guidelines for integrating trust in online stores. One of the categories is content that consist of (1) provide identity of company/seller, (2) disclose performance history/former buyer and feedback information (3) post a clear privacy and security policy, (4) provide comprehensive or accurate product and pricing Information, (5) disclose all aspect of the customer relationship upfront, (6) customer testimonials and feedback, and (7) channels of communication between consumer and vendor.

According to Cao et. al (2005) a good ecommerce web site starts with good content. The researcher suggested that good content refers to the information provided in the web site. The information has to be accurate, informative, updated and relevant to customer's need. The e-commerce web site should provide for two-way communication between users and the site, and respond quickly to users' search and browsing needs.

In a work by Liu (2000), business transactions are triggered by three criteria. One of the criteria mentioned is trustworthiness. The researcher suggested that successful e-commerce web siteis one that attracts customers, makes them feel the site is trustworthy, dependable, and reliable and generates customer satisfaction. Quality problems regarding the data or information can lead to customer dissatisfaction which can cause the decrement of trust.

\section{Methodology}

In general, the research is conducting the following methodology:-

\section{Initial Requirement Study}

This stage involves reviewing of current state of the Malaysia e-commerce blogs. Reviewing the current state of this matter, researchers would be able to have a comprehensive understanding of the subject matter. Findings from these reviews will be used as the basis to embark on this research.

\section{Sampling}

The first step is choosing the sample of potential Malaysia e-commerce blog. The overall method of choosing the potential respondent of websites is done through convenience sampling. This is due to the unavailability of a list for all Malaysia ecommerce blog. The sampling list is created by using major search engines. Several 
keywords that might hit on the Malaysia ecommerce blog are chosen for the searching purpose.

The search engine used in this study is Google. Meanwhile, the phrases that were used to search the potential blogs are:

- "Malaysia Online Store"

- "Online shopping blog"

The first 100 potential Malaysia e-commerce blogs that use BlogSpot as a medium were selected from the list that appears during the searching process. The URL of the websites is recorded for data gathering purpose. The reason why the BlogSpot-based e-commerce blog is being chosen for this study is to ensure that every e-commerce blog owner can access to the same facilities and functions provided by BlogSpot.

\section{Data Collection}

The next phase of the research is the data collection phase. The data collection techniques used for this paper is content analysis. Content analysis will be done to the selected Malaysian e-commerce blogs to identify the contents included in the particular blog. Content analysis is applied for this research as it is useful to identify trends and patterns in the blogs.

The data set were collected during October 2010. The total e-commerce blogs that had been used in this research was a 100. All of the selected e-commerce blogs were closely monitored to determine the content. List of distinct content from 100 e-commerce blog is gathered and grouped under certain criteria.
Later, the content of all e-commerce blogs will be matched to identify what is the minimum content that satisfies the list that has been gathered earlier.

\section{Analysis}

All of the data gathered in the previous phase was analyzed based on list of content that has been collected during data gathering phase. Upon analyzing the data, the information obtained from the data gathering process is presented using a descriptive statistic method. Theories from $\mathrm{Nah}$ and Davis (2002), Yang, Hu and Chen (2005) and Lumsden and MacKay (2006), as well as distinct group that is gathered from the content analysis of Malaysia e-commerce blog, will be used to group the result.

\section{Finding}

Based on the analysis, it was found that there were a few groups of contents currently being embedded by the Malaysia Ecommerce blog. Apparently, there are five groups of content, namely:

- Owner/Business Information,

- Product Information,

- Purchasing Guide,

- Postage Information, and

- Feedback.

Table 1 summarizes the description and percentage of Malaysia e-commerce blog based on every content group. 
Table 1. Information Included in Malaysia E-Commerce Blog

\begin{tabular}{|c|c|c|}
\hline Content & Description & Item \\
\hline $\begin{array}{l}\text { Owner/Business } \\
\text { Information }\end{array}$ & $\begin{array}{l}\text { Details on owner or business } \\
\text { that are shared with the } \\
\text { customer. }\end{array}$ & $\begin{array}{l}\text { i. } \quad \text { Full Name }(\mathbf{6 7 \% )} \\
\text { ii. } \text { Contact Number }(\mathbf{6 9 \% )} \\
\text { iii. Email Address }(\mathbf{9 6 \% )} \\
\text { iv. Address (34\%) } \\
\text { v. Picture }(\mathbf{3 7 \% )} \\
\text { vi. Social Networking ID (73\%) } \\
\text { vii. Chat/Instant Messenger ID (49\%) }\end{array}$ \\
\hline $\begin{array}{l}\text { Product } \\
\text { Information }\end{array}$ & $\begin{array}{l}\text { Information and description of } \\
\text { products }\end{array}$ & $\begin{array}{l}\text { i. } \text { Product Code }(\mathbf{7 9 \%}) \\
\text { ii. } \\
\text { iii. } \text { Pame/Description }(\mathbf{1 0 0 \%}) \\
\text { iv. Price }(\mathbf{9 6 \% )} \\
\text { v. Product Status }(\mathbf{6 9 \% )}\end{array}$ \\
\hline Purchasing Guide & $\begin{array}{l}\text { Instruction on how to proceed } \\
\text { with any purchase. }\end{array}$ & $\begin{array}{l}\text { i. Instructions on how to make order } \\
\mathbf{( 9 6 \% )} \\
\text { ii. Instructions on how to pay (85\%) } \\
\text { iii. Terms and Conditions (72\%) } \\
\text { iv. *Bank Account Number (52\%) } \\
\text { *Bank account number is grouped under } \\
\text { purchasing guide due to the current } \\
\text { implementation of payment. Bank account } \\
\text { number of blog owner will be given to the } \\
\text { customer for the payment. }\end{array}$ \\
\hline $\begin{array}{l}\text { Postage } \\
\text { Information }\end{array}$ & Details on postage of product & $\begin{array}{l}\text { i. Information on delivery day (70\%) } \\
\text { ii. *Proof Of Postage/Tracking number } \\
(\mathbf{3 7 \% )} \\
{ }^{*} \text { Malaysia e-commerce blog owner will post } \\
\text { the tracking number provided by postal } \\
\text { services }\end{array}$ \\
\hline Feedback & $\begin{array}{l}\text { Any communication channels } \\
\text { available on e-commerce blog } \\
\text { and feedback regarding } \\
\text { services/product/etc }\end{array}$ & $\begin{array}{ll}\text { i. } & \text { Comments/Question\&Answer/FAQ } \\
& (63 \%) \\
\text { ii. } & \text { Testimonial by existing customer }(\mathbf{3 6 \%})\end{array}$ \\
\hline
\end{tabular}

Table 2. Average (In Percentage) for Group of Information Used in Malaysia E-Commerce Blog

\begin{tabular}{|c|c|}
\hline Information & Average (\%) \\
\hline Owner/Business Information & $60.7 \%$ \\
\hline Product Information & $88.8 \%$ \\
\hline Purchasing Guide & $76.25 \%$ \\
\hline Postage Information & $53.5 \%$ \\
\hline Feedback & $57 \%$ \\
\hline
\end{tabular}


Table 2 describes the average of information based on each item in Table 1 that is used in Malaysia e-commerce blog. The percentage shows inconsistency between each of the groups. Most of Malaysia e-commerce blog owners focus more on displaying product information on their blog (88.8\%) and purchasing guide (76.25\%) compared to other groups of information. This is consistent with work by Nielsen (1999) which suggested that online company's responsibility to ensure that the product and pricing information are complete and accurate, and all other information posted on the Web site is correct and up-to-date. This allows any possible mistake should be corrected as soon as it is reported or discovered, thus increases the customer's trust.

The Owner/Business Information, Feedback and Postage information are vital and should be highlighted by all e-commerce blog owners. This is proved in work done by Davis (2002), Yang, $\mathrm{Hu}$ and Chen (2005) and Lumsden and MacKay (2006). Their work suggested that to develop trust in consumers, it is necessary for e-commerce blogs to provide the identity and complete information of the company such as their physical location, full contact information and ownership. These basic understandings of the background of the company, consumers are likely to have enough faith and confidence to do business with the ecommerce blog. Disclosure of such company information provides a sense of accountability to the consumers.

However, in Malaysia environment, only $53.5 \%$ of the e-commerce blog owner posted this information on their blog, whilst $57 \%$ for the feedback and $60.7 \%$ for the Owner/Business Information. Postage information for example, is included in a guideline posted by CourierQuote.com.au (2011), which stated customers should be promptly updated with their tracking information, whilst feedback and owner/business information are main information that will initiate trust.
What seems to be lacking in Malaysia ecommerce blog is certifications from third parties. This is important as it can increase credibility of online services. Certifications may be obtained from professional third parties such as the American Medical Association, and/or third party assurance services such as Trustee (www.truste.com), BBBOnLine (www.bbbonline.org) and VeriSign (www.verisign.com). Approvals from professional associations can enhance credibility concerning the competence of the e-commerce blog owner and the quality of services offered, while third party assurance services certify that privacy and security practices and enforcement are in place.

\section{Conclusion}

Based on the findings, we knew that the Malaysia e-commerce blog owner needs to include more information in their blog in order to instil trust among the consumers. Owner of e-commerce blog needs to be educated so that they will be aware of minimum information they should display in their blog.

According to Cao et. al (2005) that trust is the top concern of e-commerce customers. Once customers perceive that trust has been compromised, no purchase will be made. It is therefore crucial for e-commerce blog owners to understand the effect of cumulative frustration experience by the consumers that are likely to purchase, especially as it is typically in the later stages of interaction.

This research covers a modest part of broad area of trust. Therefore, an extension of work will be covering the same issues but focusing more on trust measurement of Malaysia ecommerce blog from the perspective of both of the blog owners and the consumers. Future works will also study the awareness of trust issues amongst consumers. This will call for an interesting mixture of both perspectives. 


\section{References}

Cao, M., Zhang, Q. \& Seydel, J. (2005)."B2C Ecommerce Web Site Quality: An Empirical Examination," Industrial Management and Data System. 105(5), 645-661.

Chen, H. J. (2009)."Bloggers' Social Presence Framing and Blog Visitors' Responses," 2009 Eighth IEEE/ACIS International Conference on Computer and Information Science.730735

Corbitt, B. J., Thanasankit, T. \& Yi, H. (2003)."Trust and E-Commerce: A Study of Consumer Perception," Electronic Commerce Research and Application, 2. 203-215,

CourierQuote.com.au

Ecommerce Shipping Options and Postage Tips [Online]. Retrieved February 2, 2011. http://www.courierquotes.com.au/couriers/ 101-ecommerce-shipping-options-andpostage-tips

Dwyer, P. (2007)."Building Trust with Corporate Blogs," Proceeding of International Conference on Weblogs and Social Media, Boulder CO.

Gehrke, D. \& Turban, E. (1999)."Determinants of successful website design: relative importance and recommendations for effectiveness," Proceedings of the 32nd HICSS, Hawaii.

Gregg, D. G. Supporting Web Content Quality: Formalizing Meta-Data Concepts for the Web-Domain.

Gordon, S. (2006). 'The Image of Blogging as the Preserve of the Web-Obsessed Is Fading Fast,' Computing - IEEE Review. 32-35

Hameed, S. (2001). Consumer Trust and Confidence in Internet Commerce in Internet Commerce and Software Agents: Cases, Technologies and Opportunities, Idea Group Publishing: USA.
Hsu, C. J. (2008). "Dominant Factors for Online Trust," Cyberworlds. Proceedings of International Conference on Cyberworlds. 165-172

Hsu, C.- L. \& Chuan Lin, J. C. (2008)."Acceptance of Blog Usage: the Roles of Technology Acceptance, Social Influence and Knowledge Sharing Motivation," Information \& Management, 45, 65-74.

Huizingh, E. K. (2000)."The Content and Design of Web Sites: an Empirical Study," Information and Management. 37(3). 123134

Liu, C. \& Arnett, K. P. (2000)."Exploring the Factors Associated with Web Site Success in the Context of Electronic Commerce," Information and Management. 38(1). 23-33

Lumsden, J. \& Mackay, L. (2006)."How Does Personality Affect Trust in B2C ECommerce?," Proceedings of International Conference on Electronic Commerce, August 14-16, Fredericton, Canada.

Malaysiacrunch, (2010). Malaysia ECommerce Statistic. [Online]. Retrieved December $\quad 1$, 2010. http://www.malaysiacrunch.com/2009/09/ malaysias-e-commerce-statistics.html

Misic, M. M. \& Johnson, K. L. (1999)."Benchmarking: a Tool for Web Site Evaluation and Improvement," Internet Research. 9(5).383-392.

Nah, F. F.- H. \& Davis, S. (2002)."HCI Research Issues in E-Commerce," Journal of Electronic Commerce Research. 3(3).

Nielsen, J. (1999). Trust or Bust: Communicating Trustworthiness in Web Design. [Online]. Retrieved April 9, 2011. http://www.useit.com/alertbox/990307.ht $\mathrm{ml}$

Oh, A. (2006). Two Cents Worth of ECommerce Opinion. [Online]. Retrieved 
December 31, 2006. Www.Neowave.Com.My/Sellmore/Index.Php

Plouffe, C. R., Hulland, J. S. \& Vandenbosch, M. (2001)."Research Report: Richness Versus Parsimony in Modeling Technology Adoption Decisions," Information Systems Research, 12(2), 208-222.

Proctor, R. W., Vu, K.- P. L. \& Salvendy, G. (2002)."Content Preparation and Management for Web Design: Eliciting, Structuring, Searching, and Displaying Information," International Journal of Human-Computer Interaction. 14(1): 25-92

Ratnasingam, P. (1998)."The Importance of Trust in Electronic Commerce," Internet Research: Electronic Networking Applications and Policy, 8(4). 313-321

Shergill, G. S \& Chen, Z. (2005)."Web-Based Shopping: Consumers' Attitudes Towards Online Shopping in New Zealand," Journal of Electronic Commerce Research. 6(2). 79-94

SKMM National Broadband Initiative. [Online] Retrieved Feb 1, 2011. http://www.skmm.gov.my/index.php?c=pub lic\&v=art_view\&art_id=36

Syahida Hassan \& Mohd Khairudin Kasiran. (2008). "Compliance of X.509 Certification Standard in the Implementation of Third Party Certification in Malaysia Ecommerce Websites," Communications of the IBIMA. 5(7). 42-49

Turban, E. \& Gehrke, D. (2000)."Determinants of E-Commerce Website," Human Systems Management. 19. $111-20$

Urban, G. L., Sultan, F. \& Qualls, W. J. (2000)."Placing Trust at the Center of Your Internet Strategy," MIT Sloan Management Review. 1. 39-48.

Wand, Y. \& Wang, R. Y. (1996)."Anchoring Data Quality Dimensions in Ontological
Foundations," Communications of the ACM. 39(11). 86-95.

Wang, R. Y., Reddy, M. P. \& Kon, H. B. (1995)."Toward Quality Data: an AttributeBased. Approach," Decision Support Systems. 13. 349-372.

Wan, H. A. (2000)."Opportunities to Enhance a Commercial Web Site," Information and Management. 38(1). 15-21

Winster, S. G. \& Swamynathan, S., (2010). "Blog Trust Model for Blog Readers," Proceedings of 2010 International Conference on Recent Trends in Information, Telecommunication and Computing. 314-317

Wong, C. K. (2010). An Untapped ECommerce Opportunity. [Online] Retrieved December 1 , 2010. http://www.zippycart.com/ecommercenews/1186-malaysia-an-untappedecommerce-opportunity.html

Yang, Y., Hu, Y. \& Chen, J. (2005)."A Web Trust-Inducing Model for E-Commerce and Empirical Research," Proceedings of ACM International Conference on Electronic Commerce, August 15-17, Xi'an, China.

Yee, L. H. \& Seong, L. K. (2009). Buying Via Internet. [Online]. Retrieved November 30, 2010.

Http://Biz.Thestar.Com.My/News/Story.Asp ?File $=/ 2009 / 4 / 11 /$ Business $/ 3620542$ 